\title{
Investigation of resistance and air leakage of auxiliary ventilation ducting in underground mine in Quang ninh
}

\author{
Phuong Thao Dang ${ }^{1, *}$, Zinovii Malanchuk², and Vitalii Zaiets ${ }^{2}$ \\ ${ }^{1}$ Hanoi University of Mining and Geology, 18 Vien Street, Duc Thang Ward, Bac Tu Liem District, Hanoi, Vietnam \\ ${ }^{2}$ National University of Water Management and Environment Management, 11 Soborna Str., Rivne, 33028, Ukraine
}

\begin{abstract}
Ventilation when driving roadways is one of the most important considerations in coal underground mines. Ventilation efficiency depends on fan performance and ventilation ducting system. In recent years in Vietnam, ducts have often been produced domestically. However, parameters of the duct as duct leakage, duct resistance for designing auxiliary ventilation system are referenced from abroad handbook. This lead to inaccurate design results and needs to adjust efficiency of auxiliary ventilation during driving roadways. Determination of duct resistance; air leakage in ducting system have been undertaken. The research result has been used to optimize the auxiliary ventilation system.
\end{abstract}

\section{Introduction}

The auxiliary ventilation is carried out by bringing air to the work fronts, as the track is advanced, the amount of air that reaches the front gradually decreases due to the greater resistance of the conduit and the increase of the leakage [1]. Complete elimination of air leakage from, or to the duct system is impossible due to the duct quality and numerous joints in the duct system [2].

In Vietnam, studies on an auxiliary ventilation mainly aimed at finding solutions to improve the ventilation efficiency when mining roadways driven in coal mines. The number of these works is not much, especially there is no research on the resistance and air leakage in ducting being used in coal mines. Up to now, for designing auxiliary ventilation system, duct parameters were referenced from foreign handbook. In addition, these data are published long time ago, while at present, materials as well as duct technology are much different from before that affects the optimization of the auxiliary ventilation system.

Therefore, investigation of air leakage and resistance of auxiliary ventilation ducting in underground mine in Quang ninh has been undertaken. The research result is necessary for optimizing the auxiliary ventilation system.

The parameters of the duct as duct resistance; air leakage play an important role in the design of the auxiliary ventilation.

\section{Measurement of duct resistance used in coal underground mines}

\subsection{Fundamentals of duct resistance}

Air leakage through in ducting system flows in turbulent flow mode [3]. In turbulent flow mode, airflow energy loss for overcoming viscosity of the air due to turbulent vibrations, so this level of energy loss is much higher than that in laminar flow. Pressure loss due to frictional resistance in a round duct is determined by:

$$
\Delta \mathrm{P}=\mathrm{H}=\lambda \cdot \frac{\mathrm{L}}{\mathrm{D}} \cdot \mathrm{P}_{\mathrm{v}}=32 \cdot 25 \cdot \alpha \cdot \frac{\mathrm{L}}{\mathrm{D}} \cdot \rho \mathrm{v}^{2}
$$

Where:

$\Delta \mathrm{P}$ : Pressure loss (head loss) due to frictional resistance in duct $\mathrm{L}$ long, $\mathrm{mmH}_{2} \mathrm{O}$;

$\mathrm{P}_{\mathrm{v}}$ : Velocity pressure in duct, $\mathrm{mmH}_{2} \mathrm{O}$;

$\lambda$ : Friction coefficient, dimensionless coefficient;

$\mathrm{L}$ : Distance between two cross sections of duct, $\mathrm{m}$;

$\alpha$ : Friction factor for the duct, $\mathrm{KgF} . \mathrm{s}^{2} / \mathrm{m}^{4}$;

D: Diameter of the duct, $\mathrm{m}$;

$\rho$ : Air density, $\mathrm{kg} / \mathrm{m}^{3}$;

$\mathrm{V}$ : Average velocity at the duct cross-section, $\mathrm{m} / \mathrm{s}$.

A relationship between pressure loss and friction factor in duct is given by:

$$
\frac{H}{L}=\frac{\mathrm{P}_{1}-\mathrm{P}_{2}}{\mathrm{~L}}=65.4 \cdot \frac{\alpha}{\mathrm{D}} \cdot \frac{\rho}{2}
$$

Where:

$\mathrm{P}_{1}$ : Pressure of air at section 1

$\mathrm{P}_{2}$ : Pressure of air at section 2

However, at present, there is not expression for calculating friction factor $\alpha$. It has been determined experimentally.

One of the most basic ventilation equations describes a relationship between pressure loss and airflow volume in a duct is $H=\Delta P=R \cdot Q^{2}=R$. (v.S $)^{2}$ [4] so that friction resistance in ducting system can be obtained by the following equation:

\footnotetext{
${ }^{*}$ Corresponding author: dangphuongthao@humg.edu.vn
} 


$$
\mathrm{R}=\frac{\mathrm{H}}{\mathrm{v}^{2} \cdot S^{2}}
$$

Where:

$\mathrm{R}$ : Friction resistance, $\mathrm{k} \mu$;

S: Cross sections of duct, $\mathrm{m}^{2}$ :

From equation (3), the specific resistance - $r$ and friction factor of the duct can be found:

$$
r=\frac{R}{L} \quad \text { And } \alpha=0.25 \cdot \frac{\mathrm{H} \cdot \mathrm{D}}{\mathrm{v}^{2} \mathrm{~L}}
$$

\section{Experimental procedures}

Laboratory set-up. Experimental model for determination of duct resistance was set up at Institute of Mining Science and Technology - Vinacomin (IMSAT), Uong Bi, Quang Ninh.

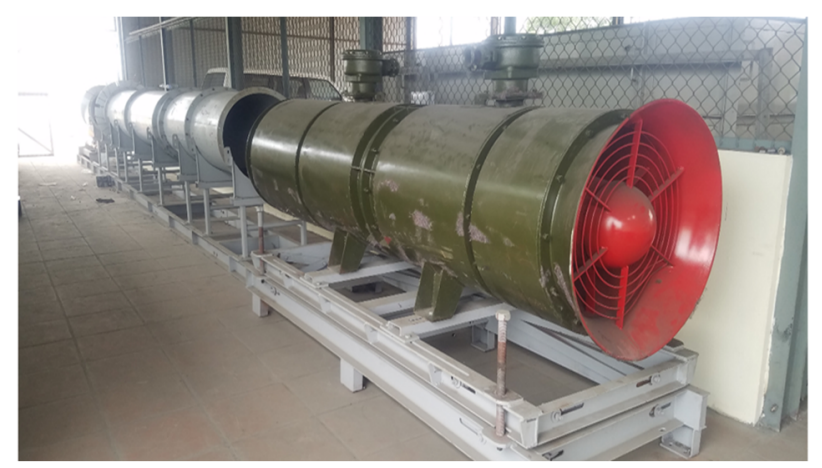

Fig. 1. Experimental apparatus for determination of duct resistance.

For the model to determine the resistance of the duct with diameter $\mathrm{D}=0.6 \mathrm{~m}$ and air flow $\mathrm{Q}=3.4 \mathrm{~m}^{3} / \mathrm{s}$, the velocity in the duct

$$
v=3.4:\left[\pi *\left(\frac{D}{2}\right)^{2}\right]=12.02 \mathrm{~m} / \mathrm{s}
$$

Reynolds number:

$$
R_{e}=\frac{v . D}{v}=\frac{12.02 * 0.6}{14.4 * 10^{-6}}=500833
$$

Where: $v$ is the viscosity coefficient of the air $v=14.4 \mathrm{x}$ $10-^{6}$

Duct length between two cross sections of duct section must be satisfied:

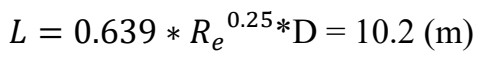

Thus, for the duct with diameter $\mathrm{D}=600 \mathrm{~mm}$, duct length is set $15 \mathrm{~m}$. Measurements were conducted on a fabric duct of $600 \mathrm{~mm}$ diameter, $15 \mathrm{~m}$ length.

Fig. 2 shows the schematic diagram for determination of duct resistance.

Fabric duct is connected directly to rigid steel ducting and carried as straight in the horizontal direction. The ducting system must be stretched tight during installation. Hence, the pressure loss on the ductwork is caused by frictional resistance [5]. Since the duct from $\mathrm{PL}_{1}$ to $\mathrm{PL}_{2}$ has no joints, local resistance does not appear.

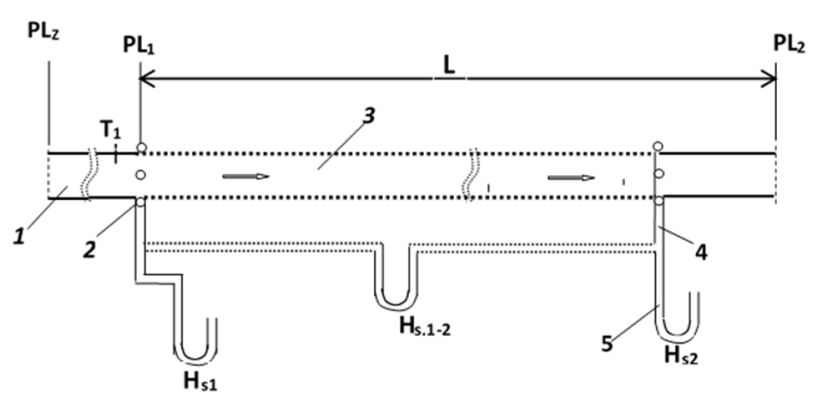

Fig. 2. Schematic diagram for determination of duct resistance: 1 - rigid steel ducting; 2 - holes for measurement; 3 - flexible fabric ducting; 4 - pitot-tube; 5 - U tube.

Velocity $\mathrm{v}$ at the center of each section was measured by a pitot tube. The cross sectional area of the duct was equally divided into four areas, 16 points traverse as shown in Fig. 3 [6].

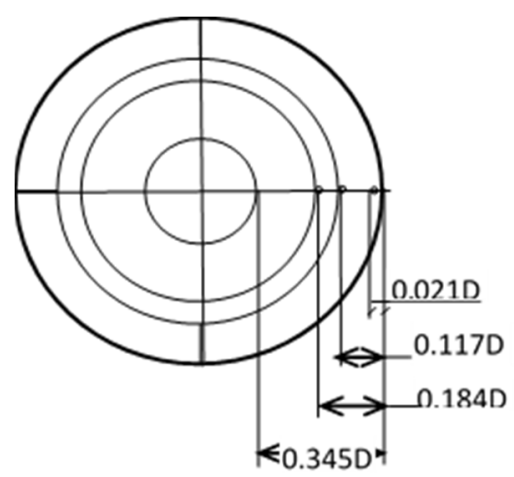

Fig. 3. Diagram position of traverse points in a circular measurement section for 4- area, 16 point traverse.

The average velocity $\mathrm{V}$ in the duct was calculated from the arithmetical mean value of $v$. At the same time, the pressure difference between the pressure $\mathrm{PL}_{1}$ and $\mathrm{PL}_{2}$ was measured and related with the average velocity $\mathrm{V}$ [7].

From that the average velocities at the measuring of the pressure drops along the ducts can be obtained.

Fig. 4 shows cross sectional area for pressure measurement and pitots in practice.

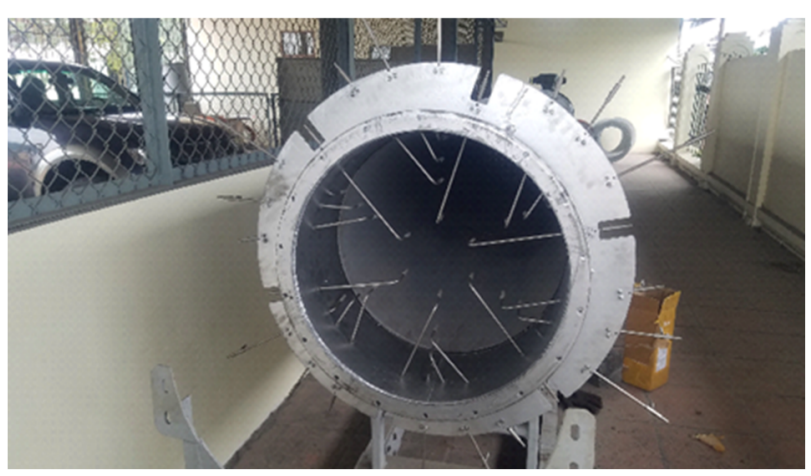

Fig. 4. Cross sectional area for pressure measurement and pitots.

\section{Test results}

Experimental data for determining duct resistance R, specific resistance $r$ and friction factors are shown in Table 1. Average values of the resistance $R$, specific 
resistance $r$ and friction factors calculated for test ducting are as:

$$
\begin{gathered}
\bar{R}=4.041 \mathrm{k \mu} ; \bar{r}=0.0269 \mathrm{k \mu} \cdot \mathrm{m}^{-1} ; \\
\bar{\alpha}=0.00030 \mathrm{KgF} . \mathrm{s}^{2} \cdot \mathrm{m}^{-4}
\end{gathered}
$$

Table 1. Experimental data and results for determining duct

\begin{tabular}{|c|c|c|c|c|c|}
\hline Measurement & 1 & 2 & 3 & 4 & 5 \\
\hline Airflow $Q, \mathbf{m}^{3} / \mathbf{s}$ & 7.33 & 7.42 & 7.42 & 7.42 & 7.43 \\
\hline $\begin{array}{l}\text { Pressure at } \\
\text { section } \mathrm{PL}_{1}, \mathrm{~Pa}\end{array}$ & 785 & 784 & 781 & 780 & 777 \\
\hline $\begin{array}{l}\text { Pressure at } \\
\text { section } \mathrm{PL}_{2}, \mathrm{~Pa}\end{array}$ & 558 & 569 & 553 & 564 & 555 \\
\hline Resistance $\mathbf{R}, \mathbf{k} \mu$ & 4.224 & 3.902 & 4.138 & 3.921 & 4.0201 \\
\hline $\begin{array}{l}\text { Specific } \\
\text { resistance } r \\
\text { k } \mu / \mathbf{m}\end{array}$ & 0,02816 & 0,02602 & 0,02759 & 0,02610 & 0.02680 \\
\hline $\begin{array}{c}\text { Friction factor } \alpha \\
\mathrm{KgF} . \mathbf{s}^{2} / \mathbf{m}^{4}\end{array}$ & 0.00034 & 0.0031 & 0.00033 & 0.0003 & 0.00032 \\
\hline
\end{tabular}
resistance.

The values for the measured friction factor is small compare with published values calculated by others as shown in Table 2 [8]. However, the measured friction coefficient $\left(0.0003 \mathrm{kgF} . \mathrm{s}^{2} / \mathrm{m}^{4}\right)$ is much smaller with the value using the auxiliary ventilation design in Vietnam $\left(0.00048 \mathrm{kgF} . \mathrm{s}^{2} / \mathrm{m}^{4}\right)$.

Friction factor depends on the smoothness of the duct material, diameter as well as the tension level of the ducting system.

Table 2. Quoted friction factors for flexible duct.

\begin{tabular}{|c|c|l|}
\hline No & $\begin{array}{c}\text { Friction Factor, } \\
\mathrm{KgF}, \mathrm{s}^{2} / \mathrm{m}^{4}\end{array}$ & \multicolumn{1}{|c|}{ Reference } \\
\hline $\mathbf{1}$ & $\begin{array}{c}0,00054 \\
0.00046-0.00048\end{array}$ & $\begin{array}{l}\text { Telyakovsky and Komarov, 1969 } \\
\text { Burtrakov and Ushakov }\end{array}$ \\
\hline $\mathbf{2}$ & 0.00030 & Le Roux, 1979 \\
\hline $\mathbf{3}$ & $0.00037-0.00046$ & Hartman and Mutmanski, 1982 \\
\hline $\mathbf{4}$ & 0.00051 & Baret and Wallman, 1983 \\
\hline $\mathbf{5}$ & 0.00023 & Jones and Rodgers, 1983 \\
\hline $\mathbf{6}$ & 0.00038 & Vutukuri V., 1983 \\
\hline $\mathbf{7}$ & 0.00030 & $\begin{array}{l}\text { Institute of Mining Science and } \\
\text { Technology - Vinacomin , Vietnam }\end{array}$ \\
\hline
\end{tabular}

\section{Estimation of air leakage of duct used in coal underground mines}

Level of air leakage is mainly influenced by the following factors: total length, diameter of the ducting and airflow in the ducting system. The experimental data are made on $0.6 \mathrm{~m}$ diameter ducts over sections of ducts installing towards the working face in actual field conditions in Quang Ninh coal mine as shown in Tab.3. A conceptual prediction model has been proposed based on experimental data at Quang Ninh Coal mine [9].

$$
p=f(L, Q)
$$

Let $\mathrm{p}, \mathrm{L}$ and $\mathrm{Q}$ represent leakage coefficient, duct length and quantity of airflow in the ducting system respectively. It is assumed to express $p$ in the form:

$$
\ln (p-1)=\ln c+b_{1} \ln L+b_{2} \ln Q
$$

Where: $p$ : Leakage coefficient;

L: Duct length, m;

Q: Quantity of airflow in the ducting system, $\mathrm{m}^{3} / \mathrm{s}$;

lnc, $b_{1}, b_{2}$, constants.

Each set of data: $\ln \left(\mathrm{p}_{\mathrm{i}}\right), \ln \left(\mathrm{L}_{\mathrm{i}}\right)$ and $\ln \left(\mathrm{Q}_{\mathrm{i}}\right)$ under given data - duct diameter, with $\mathrm{i}=1,2 \ldots \mathrm{n}$.

With ducting length $\mathrm{L}_{\mathrm{i}}$, the quantity of airflow in the ducting system $\mathrm{Q}_{\mathrm{i}}$ is measured; the air leakage coefficient $p_{i}$ is calculated as $p_{i}=\frac{Q_{0}}{Q_{i}}$;

Where: $\mathrm{Q}_{0}$ the quantity of airflow beyond the fan, $\mathrm{m}^{3} / \mathrm{s}$;

\begin{tabular}{|c|c|c|c|c|c|}
\hline $\mathbf{L}(\mathrm{m})$ & 1.5 & 2 & 2.5 & 3 & 3.5 \\
\hline 100 & 1.022 & 1.025 & 1.028 & 1.030 & 1.032 \\
\hline 200 & 1.081 & 1.091 & 1.100 & 1.108 & 1.115 \\
\hline 300 & 1.173 & 1.195 & 1.214 & 1.230 & 1.245 \\
\hline 400 & 1.296 & 1.333 & 1.365 & 1.394 & 1.420 \\
\hline 500 & 1.448 & 1.505 & 1.554 & 1.597 & 1.636 \\
\hline 600 & 1.630 & 1.709 & 1.778 & 1.839 & 1.894 \\
\hline 700 & 1.839 & 1.945 & 2.037 & 2.118 & 2.192 \\
\hline 800 & 1.455 & 2.213 & 2.330 & 2.434 & 2.529 \\
\hline 900 & 2.341 & 2.511 & 2.657 & 2.786 & 2.904 \\
\hline $\mathbf{L}(\mathrm{m})$ & 4 & 4.5 & 5 & 5.5 & 6 \\
\hline 100 & 1.033 & 1.035 & 1.037 & 1.038 & 1.040 \\
\hline 200 & 1.122 & 1.128 & 1.133 & 1.139 & 1.144 \\
\hline 300 & 1.259 & 1.272 & 1.284 & 1.296 & 1.307 \\
\hline 400 & 1.443 & 1.466 & 1.486 & 1.506 & 1.524 \\
\hline 500 & 1.672 & 1.706 & 1.737 & 1.767 & 1.795 \\
\hline 600 & 1.945 & 1.000 & 2.036 & 2.078 & 2.117 \\
\hline 700 & 2.259 & 2.322 & 2.381 & 2.436 & 2.489 \\
\hline 800 & 2.615 & 2.696 & 2.771 & 2.843 & 2.910 \\
\hline 900 & 3.012 & 3.113 & 3.207 & 3.295 & 3.379 \\
\hline
\end{tabular}

$\mathrm{Q}_{\mathrm{i}}$ the quantity of airflow reaching the end of the ducting length $-\mathrm{L}_{\mathrm{i}}$.

Table 3. Experimental data for the duct of $0.6 \mathrm{~m}$ diameter.

Let $\mathrm{y}_{\mathrm{i}}, \mathrm{x}_{\mathrm{i} 1}, \mathrm{x}_{\mathrm{i} 2}$ and $\mathrm{b}_{0}$ represent $\ln \left(\mathrm{p}_{\mathrm{i}}-1\right), \ln \mathrm{L}_{\mathrm{i}}, \ln \mathrm{Q}_{\mathrm{i}}$ and $\ln C$ respectively. Equation above can be rewritten:

$$
y_{i}=b_{0}+b_{1} x_{i 1}+b_{2} x_{i 2}
$$

Least-squares regression is to fit these experimental data that minimizes the sum of squared residuals [10]:

$$
\sum_{i}^{n} e_{i}^{2}=\sum_{i=1}^{n}\left(y_{i}-b_{0}-\sum_{j=1}^{2} b_{j} x_{i j}\right)^{2}
$$

Take derivatives with respect to the model parameters $b_{0}, b_{1}$ and $b_{2}$ set them equal to zero and derive the leastsquares normal equations that our parameter estimates $b_{0}$, $b_{1}$ and $b_{2}$ would have to fulfil.

Normal equations of two independent variables can be written in matrix form as:

$\left|\begin{array}{cc}\sum_{i=1}^{n} x_{i 1}^{2} & \sum_{i=1}^{n} x_{i 1} x_{i 2} \\ \sum_{i=1}^{n} x_{i 1} x_{i 2} & \sum_{i=1}^{n} x_{i 2}^{2}\end{array}\right|\left|\begin{array}{l}b_{1} \\ b_{2}\end{array}\right|=\left|\begin{array}{c}\sum_{i=1}^{n} x_{i 1} y_{i} \\ \sum_{i=1}^{n} x_{i 2} y_{i}\end{array}\right|$

Solve the above matrix to obtain the regression coefficients. Therefore, the air leakage coefficient for the 
duct of $0.6 \mathrm{~m}$ diameter can be obtained based on data at Quang Ninh mine:

$$
\mathrm{p}=1+3.5078 \cdot 10^{-6} \cdot \mathrm{L}^{1.865} \mathrm{Q}^{0.4135}
$$

Use the F-test can evaluate Pro $(F)=0.0000$ with significance level is 0.5 . This low a value would imply that the regression parameters are nonzero and the regression equation does have some validity in fitting the data.

\section{Conclusion}

The resistance and air leakage of the duct depends on many factors, in which the ducting material and size play an important role.

For designing auxiliary ventilation system, duct parameters were referenced from foreign handbook that causes results in lack of confidence.

Factors such as duct size and diameter, aerodynamic parameters in duct airflow influence on duct air leakage.

A conceptual prediction mode can be determined duct air leakage based on the experimental data at Quang Ninh mine. Also, the research result has been used to optimize the auxiliary ventilation system. Optimization of the auxiliary ventilation system can save cost and energy.

Authors would like to thank to Quang Ninh coal companies for the support with site access and field investigation. This work was financially supported by Hanoi University of Mining and Geology.

\section{References}

1. Vutukuri, VS, Design of auxiliary ventilation systems for long drivages, Proceedings of the Fifth Australian Tunneling Conference, Institution of Engineers,Sydney, pp. 73-79, (1984)

2. Onder, M., Sarac, S. and Cevik, E., The influence of ventilation variables on the volume rate of airflow delivered to the face of long drivages. Tunnelling and Underground Space Technology, 21(5), pp. 568-574, (2006)

3. Ushakova, U.Z. et al. Mine aerology (1988)

4. McPherson, MJ 1993, Subsurface Ventilation and Environmental Engineering, Chapman \& Hall, London, (1993)

5. Shim, G., Song, L. and Wang, G., Comparison of different fan control strategies on a variable air volume systems through simulations and experiments. Building and Environment, 72, pp. 212222, (2014)

6. Kingery, D.S., Introduction to Mine Ventilating Principles and Practices, US Bureau of Mines Bul (US Bureau of Mines, Washington DC), (1960)

7. IMSAT - Vinacomin Handbook, Research and build a testing station of auxiliary fan characteristics and duct resistance (2017)
8. A.D.S. Gillies and Hsin Wei Wu. A comparison of air leakage prediction techniques for auxiliary ventilation ducting systems. Proceedings Eighth US Mine Ventilation Symposium, Society of Mining Engineers, pp 681-690 (June 1999)

9. Phuong Thao Dang, Research project supported by Hanoi University of Mining and Geology, A study on relationship of duct leakage and parameters of ducts in Quang Ninh mine, (2018)

10. Douglas C. Montgomery, Elizabeth A. Peck, G. Geoffrey Vining, Introduction to linear regression, Wiley; Fifth edition (Mar. 2012) 